\title{
Engineering Innovation (EI) and Network Operation
}

\author{
Yufeng Zhang* \\ University of Birmingham, United Kingdom
}

*Corresponding author: Yufeng Zhang, University of Birmingham, United Kingdom,

,Email: Zhangys@bham.ac.uk

Received Date: March 27, 2019

Published Date: April 08, 2019

\section{Introduction}

Civil engineering operations are experiencing structural changes throughout the value chain. At the upstream, major engineering companies consolidate their global operations with aggressive mergers and acquisitions. Examples in 2017 include Jacob's acquisition of CH2M Hill, SNC-Lavalin's acquisition of Atkins, and John Wood's acquisition of Amec Foster Wheeler. At the downstream, large construction companies are on the brink of crisis as exemplified by Carillion's liquidation in 2018 and Wanda's reform towards asset-light service operations [1]. These changes, which are often intertwined with unprecedented digital transformations brought by new possibilities such as Big Data Analytics, Artificial Intelligence and Internet of Things, prompt us to rethink whether the current operations capabilities for civil engineering are still useful and keeping up with the actual need of competition [2].

For survival and prosperity in the 21st century, companies need to gain network capabilities for engineering innovation at the project and organisation levels [3]. Engineering Innovation (EI) in this context stands for a multidisciplinary approach for creating high value-added products, services and solutions based on systematic engineering capabilities. These capabilities are underlying forces for the long-term prosperity of a company through directly contributing to its profitability and indirectly improving the performance of manufacturing and servicing functions. At the project level, the emergence of dynamic project networks suggests useful elements of EI capabilities. These engineering networks provide a digital environment for dispersed working units to complete a large-scale construction project on a temporary basis. Network members can access embedded knowledge dispersed around the world and ensure accountability of different project teams via a collaborative venture. In doing so, they will benefit from innovative ideas across technological and disciplinary boundaries and hence driving the performance of EI towards a higher level. The design and operations of these engineering networks in an international context may benefit from the geography economic models for global production networks [4] and the governance frameworks of global value chains [5] with necessary adaption.

At the organisation level, the service-dominant logic [6] suggests an alternative mind-set to gain network capabilities for EI in civil engineering operations. New practice of engineering service networks indicates the latest trends of EI among networks of professional engineers. Engineering service operations in general are facing a significant archetypal change from the traditional organizational model of a professional partnership to a more knowledge-based, technology-enabled, globally-networked organisation. Engineering service providers are pioneering new forms of network based organisation as a result of the nature of the knowledge they deploy, the degree of jurisdictional control they exercise, and the global client relationships they seek [7]. From a knowledge perspective, engineering service providers tend to adopt lateral team structures and reciprocal processes since they have a technical or syncretic knowledge base supported by multiple disciplines rather than a normative knowledge base. From a jurisdiction perspective, engineering professions have weaker social closure and looser geographic jurisdictional boundaries; therefore, it is relatively easy for engineering companies to form a global network structure. From a client perspective, engineering service operations require a high degree of face-to-face client interaction, and thus a high degree of geographic dispersion of assets especially when the clients are geographically dispersed. In parallel with the aforementioned dynamic engineering project networks, it is clear that service oriented network organisations play an increasingly important role in EI driven by the expansion of major engineering companies, increasing geographic dispersion of engineering capabilities (including the human capabilities embedded in the work force), and opportunities made available by collaborative infrastructural investments, e.g. projects around the Belt and Road Initiative (http://english.gov.cn/beltAndRoad). 
With progress of developing their global network capabilities for EI, engineering companies face critical operations challenges in organizing and coordinating dispersed engineering activities across geographic and organizational boundaries. The challenges are compounded by ongoing digital transformations as well as the fact that engineering capabilities are knowledge intensive, project based, people centric and process embedded [8]. These difficulties and challenges can be addressed within a systematic framework of network capabilities [9] centralized on accessing and deploying dispersed resources, coordinating interrelated activities, and collaborative learning with network partners worldwide. In addition engineering companies should pay attention to the distinctive features of engineering operations, which in general lead to a negative relationship between international expansion and the resulting financial return [10]. Their decision-makers are suggested to balance the need for long-term strategic gains and short-term financial payoffs, and at the same time leverage growth and performance through strategic resource decisions in global network operations.

\section{Acknowledgement}

None.

\section{Conflict of Interest}

No conflict of interest.

\section{References}

1. Wang J (2019) Chairman Wang Jianlin's Work Report at 2019 Wanda Annual Conference. Wanda Group Press Releases, Beijing, China.

2. Brynjolfsson E, McAfee A (2014) The Second Machine Age: Work, Progress, and Prosperity in a Time of Brilliant Technologies. WW Norton \& Company, New York, USA.

3. Zhang Y, Gregory M (2018) Value Creation through Engineering Excellence: Developing Network Capabilities. Palgrave McMillian, London, UK.

4. Yeung H, Coe NM (2015) Toward a Dynamic Theory of Global Production Networks, Economic Geography 91(1): 29-58.

5. Gereffi G, Fernandez-Stark K (2016) Global Value Chain Analysis. Centre on Globalisation. Governance\& Competitiveness, Duke University, Boston, USA.

6. Vargo SL, Lusch RF (2017) Service-dominant logic 2025. International Journal of Research in Marketing 34: 46-67.

7. Malhotra N, Morris T (2009) Heterogeneity in professional service firms. Journal of Management Studies 46(6): 895-922.

8. RAEng (2010) Philosophy of Engineering. The Royal Academy of Engineering, London, UK.

9. Zhang Y, Gregory M, Neely A (2016) Global Engineering Service: Shedding Light on Network Capabilities. Journal of Operations Management: 42$43,80-94$.

10. Zhang Y, Yang Z, Zhang T (2018) Strategic Resource Decisions to Enhance the Performance of Global Engineering Services. International Business Review 27(3): 678-700. 